\title{
Gender and conversational dominance in Japanese conversation
}

\author{
H I R O K O I T A K U R A \\ Department of English \\ The Hong Kong Polytechnic University \\ Hung Hom, Kowloon, Hong Kong \\ eghiroko@polyu.edu.hk \\ A M Y B. M. T S U I \\ Faculty of Education \\ The University of Hong Kong \\ Pokfulam Road, Hong Kong \\ bmtsui@hku.hk
}

A B S T R A C T

A number of studies have been conducted on "dominance" as reflected in spoken interactional features, most of which deal with English. Many of these studies adopt a quantitative approach, examining the amount and distribution of interactional features such as amount of talk, interruptions and overlaps, turn-taking, questions, and topic initiations, and they have drawn conclusions on "dominance" accordingly. The present study explores gender dominance in conversation by analyzing conversational data from eight Japanese dyads by integrating quantitative and qualitative analyses. The quantitative analysis of two dimensions of conversational dominance, sequential dominance and participatory dominance, does not show any obvious gender dominance; however, the qualitative analysis of three of the dyads finds a clear pattern of male speakers' self-oriented conversational style, which is manifested in their storytelling and claiming expertise, and this is supported by female speakers' other-oriented conversational style. Gender dominance therefore is seen as a mutual construction. The conclusion discusses the importance of integrating findings from both quantitative and qualitative analyses in situated contexts to deepen understanding of the complexity of gender dominance. (Japanese conversation, gender, conversational dominance, conversational orientation, conversational style.)*

\section{N T R O D U C T I O N}

Studies of the effects of gender and social dominance on conversational interaction in English have suggested that the domination of male over female is manifested in various ways in this context as a micro-institution, just as it is 
manifested in macro-institutions (e.g., DeFrancisco 1998, West \& Zimmerman 1983, West \& Garcia 1988, Woods 1988, Zimmerman \& West 1975). Studies of gender dominance have identified interactional features that are indicative of conversational dominance, such as overlap, interruption, topic change, turn length, and distribution of number of turns, and researchers have conducted quantitative analyses of the distribution of such features. For example, Zimmerman \& West 1975, 1983 found that, although the distributions of overlaps and interruptions were more or less equal in single-sex conversations, in mixed sex-conversations all the overlaps and $98 \%$ of the interruptions were made by male speakers (for critiques of Zimmerman \& West, see Murray 1988, Murray \& Covelli 1988). West \& Garcia 1988 analyzed topic change in conversational data from mixedsex dyads of university students and found that only male speakers initiated unilateral topic changes. DeFrancisco's study (1998) of mixed-gender conversations from seven married couples shows that the men interrupted and withdrew responses more frequently than women did (see also Fishman 1983).

The ways in which research into gender dominance in conversation has been conducted are problematic for the following reasons. First, in these studies inequality in power and social status between men and women is seen to be reflected in the distributional analyses of interactional features of conversational dominance. Interactional features of a particular type are treated as a sign of dominance, and they are aggregated without considering the specific contexts in which they occur. However, interruptions, for example, can be of different types with varying degrees of control. An interruption can be resisted by the current speaker who holds onto his or her turn-at-talk, resulting in the interrupter's yielding the floor. This kind of interruption is different from one that successfully causes the current speaker to yield the floor. Similarly, although questions can be considered as controlling in the sense that they constrain what counts as an appropriate subsequent contribution, the degree to which they control the interlocutor's following contribution is different between questions that obtain a response and those that fail to do so (for a discussion of signs of dominance, see Itakura 2001a, 2001b; Linell et al. 1988). Identification of the interactional features of dominance, therefore, needs to be revised so as to be more context-sensitive.

Second, interactional features identified as signs of dominance can in fact be motivated by different conversational goals. For example, an interruption can usurp the current speaker's turn-at-talk and therefore can indicate dominance, but it can also reflect a highly participatory style in which the interrupter's conversational goal is to be a supportive conversationalist (see Coates 1997, James \& Clarke 1993, Tannen 1986, 1994). Murray \& Covelli's study (1988) on interruptions and gender in different contexts also suggests that interruption may be related more strongly to conversational styles ("behavioural repertoire") rather than to dominance.

The intersection of conversational style and gender difference has been extensively studied by Tannen 1986, 1990, 1994 (see also Coates 1996, 1997). Tannen 
claims that women's conversational style is characterized by their tendency to speak and hear a language in terms of "connection and intimacy," while men tend to speak and hear a language in terms of "status and independence" (Tannen 1990:42). Hence, females try to establish rapport by emphasizing similarities and matching experiences, whereas males tend to assert their independence and status by "exhibiting knowledge and skill, and by holding center stage through verbal performance such as story-telling, joking, or imparting information" (Tannen 1990:77). Moreover, males tend to be more oriented to themselves and to downplay the concerns expressed by their interlocutors. They tend to lead rather than support the conversation. Style differences seem to be related to differing use of the same interactional features. For example, Coates 1996, 1997 writes that women tend to use "other-oriented" questions (referred to as "addressee-oriented" questions by Holmes 1984, 1995), which include questions used to invite others into talk, to extend the topic under discussion, and to avoid playing the expert. In contrast, men tend to ask speaker-oriented questions that are used to seek information, to demonstrate power and expertise, and to introduce new topics (on conversational style and orientation, see also Hirschman 1973, 1994; Tannen 1994).

More recent studies on gender and language suggest that gender dominance is a social construction (Baron \& Kotthoff 2002, Kiesling 1998, Wodak 1997, West $\&$ Fenstermaker 2002). They reveal how it is achieved, maintained, and reproduced by speakers by taking full account of its context. Quantitative analyses alone, therefore, cannot reveal the complex relationship between conversational dominance and style and associated features. Kiesling 1998, a study of a meeting of an American college fraternity, is interesting in this respect because it demonstrates how quantitative and qualitative analyses of a social variable can be usefully combined in order to understand how men's identities are constructed. ${ }^{1}$

A fuller picture of gender dominance in conversation, therefore, needs refinement of the analytical framework for its quantitative analysis. Findings of quantitative analysis need to be triangulated and interpreted in light of qualitative analysis of conversational styles and orientations. The questions that this article addresses are, first, in what ways can the operationalization of conversational dominance be refined to take into account the specific contexts in which the interactional features occur? Second, how far can quantitative analyses of these features capture conversational dominance, and what insights can qualitative analyses of the same interactional features provide?

To address these questions, the study reported here uses as data for investigation conversations between Japanese men and women, because gender plays a central role in determining relationships in Japanese culture (Ide 1992. Okamoto 1995, Uchida 1997). The data set consists of conversations produced by eight mixedgender dyads of Japanese university students. We will focus on two dimensions of conversational dominance: The first relates to the nature of the turns taken and is referred to as "sequential dominance"; and the second relates to participation and is referred to as "participatory dominance." (For a detailed explanation of these 
two dimensions, see the following sections.) We propose a framework of analysis that takes into account the specific context in which the interactional features occur in these two dimensions. A quantitative analysis of sequential dominance showed no significant male dominance over female, but significant female dominance over male in one of the eight dyads. As for participatory dominance, male dominance over female was observed in two of the dyads, and female dominance in one of the dyads. A qualitative analysis of two dyads in each dimension revealed that the male participants in these dyads consistently showed a strong selforientation in conversation, and the female participants a strong other-orientation (see also Uchida 1992). It also showed that interaction between the male participants' self-orientation and the female participants' other-orientation contributed to male dominance (see also DeFrancisco 1998, Kendall \& Tannen 1997).

The findings suggest that conversational dominance is constructed through interaction between the different conversational orientations and styles of male and female, leading to its complex and multifaceted nature, and that its interactional features are situated in highly specific contexts. Quantitative analyses of the relative distribution of interactional features should be interpreted in the conversational context of which the interactional features are a part. They should also be complemented by qualitative analyses of these features that consider the larger social and cultural context that shapes and is shaped by conversation.

FR AMEWORK OF A NALY IS

The term "dominance" in this article refers to manifest (observable) dimensions or structures in dialogue and discourse (see Linell 1990, Linell et al. 1988). The framework proposed in this study draws on Linell et al. 1988, who observe that dominance is multidimensional because there are many ways in which a party can be considered to "dominate" in the shared construction of conversation, in the sense of possessing or controlling the "territory" to be shared by the communicating parties (1998: 158). Conversational dominance in the present study is therefore seen from the point of view of the interactional effect of controlling action during conversation, rather than that of speaker intent (Tannen 1994, Gunnarsson 1997). Unlike Linell and his collaborators, we distinguish between attempts to perform controlling actions that are successful and those that are not. Only the former would be considered as indicative of conversational dominance.

This study focuses on interactional features that are commonly identified as indicative of conversational dominance, such as initiations, overlaps, and interruptions. We will subsume them under two dimensions, sequential dominance and participatory dominance, explained below (see also Itakura 2001b).

\section{Sequential dominance}

The term "sequential dominance" refers to one speaker's tendency to control the other speaker with respect to the direction of the interaction. This is evidenced by 
how the speakers share initiating and responding moves, and by how often a speaker makes initiating moves, because a speaker who makes an initiation determines what constitutes an appropriate response (see Schegloff \& Sacks 1973, Coulthard \& Brazil 1981, Rommetveit 1987). As Linell argues, "Asking questions is a matter of trying to condition the other's contributions more or less strongly, whereas simply answering questions may amount to little more than just complying with the other's conditions" (1990:153). Moreover, as Linell further points out, although initiatives and responses are local events, the aggregated patterns of initiatives and responses emerging over sequences of utterances will indicate the dominant party in the conversation. The significance of initiations for topic determination and conversational dominance has also been noted by Sacks as follows: "The person who is asking the questions seems to have first rights to perform an operation on the set of answers. You can call it ddraw a conclusion'... As long as one is in the position of doing the questions, then in part they have control of the conversation" (1992a:54).

In this study, sequential dominance is defined as an overall pattern in which one speaker tends to control the direction of the conversation. This is measured by the way in which the speakers share initiating and responding moves. Following Sinclair \& Coulthard 1975, we define each turn as one or more than one move. Hence, a speaker who responds to a preceding question and then asks a question in the same turn will be performing two moves.

In investigating sequential dominance, we propose the concept of "controlling action" (see Linell et al. 1988, Linell 1990, Linell \& Luckmann 1991), which is defined as an action that has the effect of restricting the other speaker's contribution to the development of the conversation (referred to as "sequential controlling action" or SCA). If an initiation is followed by a complying action - that is, the next speaker produces a "prospected response" (see Sinclair \& Coulthard 1975, Tsui 1994) - then the first speaker has successfully performed a controlling action over the next speaker in terms of sequential dominance. We shall refer to such a sequence as "sequential successful controlling action" (SSCA). If an initiation is not followed by a complying action - that is, the next speaker makes another initiation instead of producing the prospected second pair-part, or challenges the presupposition in the initiation - then it is treated as an instance of "sequential attempted controlling action" (SACA). Instances of SACA are not treated as contributing to dominance in conversation because they fail to control the other speaker's conversational actions.

The description of initiations in this paper is based on Tsui 1994, who classifies initiations as "requestives," "directives," "elicitations," and "informatives." Requestives and directives prospect a nonverbal action from the next speaker; a requestive offers the option of complying or not complying, whereas a directive does not. Elicitations subsume all utterances that elicit a verbal response. Elicitations can be in the form of interrogatives, tag-questions, or declaratives. Informatives include all utterances that prospect an acknowledgment or a comment. 
They subsume reports (Drew 1984) and assessments (Pomerantz 1978, 1984), which can be positive or negative evaluations of the speaker, the other speaker, or a third party (see Tsui 1991, 1994).

Example (1) is an excerpt from the data that illustrates instances of SSCA and SACA:

(1) Dyad 3: M3 was telling F3 about his private student who is very weak in Japanese.

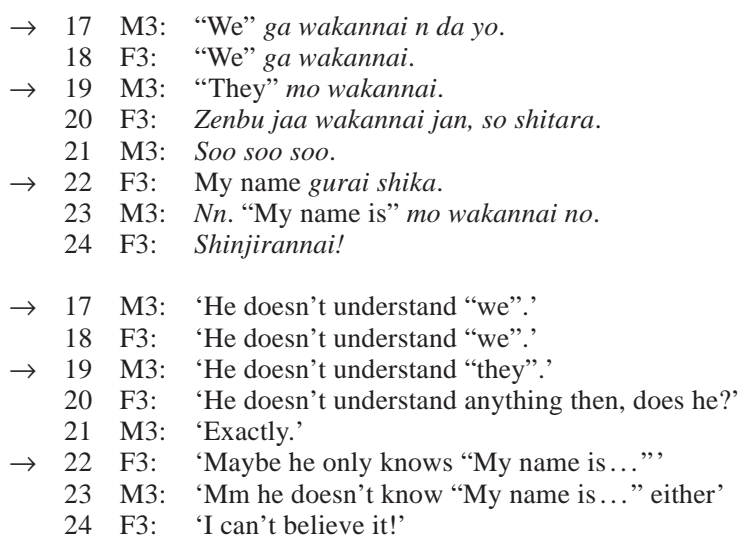

In turn 17, M3 produces an informative in which he makes a negative evaluation of his private student. This is acknowledged by F3 in turn 18 by echoing the evaluation. Turn 17 is therefore an SSCA. Turn 19 is also an SSCA because in turn 20, F3's tag question is spoken with falling intonation and functions as an acknowledgment of M3's negative evaluation by upgrading not understanding "they" to not understanding "anything." This is a common type of response to evaluative statements (see Pomerantz 1984). That F3's response was prospected can be seen from M3's total agreement with her upgrade. Turn 22 is a SACA because F3's assessment of the student as knowing only how to say 'My name is ...' in English is challenged by M3, who points out that he does not even know that. Hence, she fails to elicit a prospected response that agrees with her statement.

Dominance on the sequential dimension is measured by comparing the proportions of SSCAs achieved out of the total number of SCAs performed by the male and the female speakers. If the male speaker achieved a significantly higher proportion of SSCAs than the female speaker, he would be considered to have dominated her.

\section{Participatory dominance}

The term "participatory dominance" refers to one speaker's tendency to control the other speaker's participation in interaction by restricting his or her speaking 
rights, in particular through interruptions, overlaps, and completion offers (Grimshaw 1987; these are referred to as "appendors" by Sacks 1992a, 1992b).

Following Zimmerman \& West 1975 and West \& Zimmerman 1983, we define "interruption" here as simultaneous speech that results when a second speaker begins to speak in the middle of a current speaker's utterance, and not at the first possible completion point (or transition-relevant place). "Overlap" denotes simultaneous speech that results when a speaker begins to speak at or very close to a transition-relevant place in a current speaker's utterance. Although interruptions are often viewed as violations of the turn-taking rule whereas overlaps occur at a legitimate place for speaker alternation, they are similar in that they may affect the other speaker's participatory rights.

Again, taking into consideration how interruptions, overlaps, and completion offers are related to their immediate discourse context, we consider them as indicators of dominance only if the speaker is successful in maintaining the floor and getting the other speaker to relinquish it. Using the notion of controlling action, a speaker is considered to have successfully performed the controlling action in participation (participatory successful controlling action, or PSCA) if he or she succeeds in completing a turn-at-talk and in getting the other speaker to withdraw. If, instead, the speaker who interrupts, overlaps, or offers a completion of the current speaker's turn has to relinquish the floor, then this is considered a participatory attempted controlling action (PACA) and does not contribute to participatory dominance.

The following excerpt from the data illustrates instances of PSCA and PACA:

(2) M3 and F3 were talking about the hourly rate paid for private tuition.

67 F3: Kateikyooshi demo shiyoo ka naa. Demo saa oshierannai n da mon. Atashi jibun de kangaechau kara, kitto.

68 M3: Att demo kekkoo soo yиu no aru yo ne. Iya tte yori ka wasurechatteru.

69 F3: Demo sono gurai dattara sa jibun ga wakannakute mo sa mukoo mo wakannai shi anmari rikaishite kunnai kara, sonnani...

70 M3: yatte n no. Wakannai toki kore koo naru no toka itte.

71 F3: A sokka. Soo da yo nee.

67 F3: 'I wonder if I should offer private tutoring. But you know I can't teach. I would probably think too much.'

68 M3: 'Ah but that's quite possible. I mean, we've rather forgotten a lot.'

69 F3: 'But at that level, even if I don't understand, since the student won't understand either and er he doesn't understand very much, so not very...'

70 M3: 'Exactly. I take it easy. When I don't understand, I say something like "It's like this".'

71 F3: 'Oh I see. That's right.' 
In turn 69, F3 interrupts M3 soon after the first transition-relevant place. However, instead of withdrawing, M3 continues to complete his turn (turn 68). Turn 69, therefore, is an instance of PACA. In turn 70, M3 interrupts F3, also before a possible transition-relevant place, and F3 relinquishes the floor soon after M3's interruption and M3 completes his turn. Turn 70 is therefore an instance of PSCA. The same principle applies to overlaps. One speaker may insist on completing the turn and the other speaker may then withdraw, in which case the former will have successfully performed a controlling action over the latter. Alternatively, both of them may hold onto their turns, in which case neither will have established control over the other.

Participatory dominance is measured by comparing the proportions of PSCAs achieved out of the total number of PCAs performed by the male and the female speakers. The speaker who achieves a significantly higher proportion of PCAs is considered to have dominated the other party.

\section{DATA COLLECTION}

The participants in this study consisted of eight males and eight females in the same age group, all first-year undergraduate students at Kanda University of Foreign Languages in Chiba, near Tokyo. The participants did not know each other well when the recording took place in June, which was approximately two months after they entered university. Therefore, there is minimal difference within and across the dyads in two variables, age and social distance, that may affect interactional dynamics.

To investigate the effect of gender on conversational interaction, the participants were grouped into eight mixed-gender dyads. A list of topics familiar to both participants, such as university life, food, and part-time jobs, were given to them. The aim was to minimize the possibility of one speaker's dominating another because he or she had greater knowledge of the topic (LeetPellegrini 1980). They were allowed to choose any topic that they wanted to talk about in Japanese for approximately 10 minutes. Each dyad was free to discuss the topic in whatever way they wished. The participants were not told the purpose of the recording. Each dyadic conversation was recorded and transcribed verbatim.

Although the conversations were recorded in a quasi-experimental setting and hence cannot be considered naturally occurring in a strict sense, the transcripts of the data show that the recording setting did not seem to cause any unnaturalness in the discourse. In order to ensure that the data captured their behavior when they were fully involved in the conversation, approximately the last 100 turns were selected from each of the 8 dyadic conversations for analysis (the number ranged from 98 to 102 turns, to make sure that each data set started and ended with a complete exchange). 
TABLE 1. Sequential dominance: number of SSCAs and SACAs produced by male and female speakers in mixed gender dyads.

\begin{tabular}{|c|c|c|c|c|c|c|c|}
\hline \multirow[b]{2}{*}{ Dyad } & \multicolumn{3}{|c|}{ Male } & \multicolumn{3}{|c|}{ Female } & \multirow[b]{2}{*}{$p^{\text {a }}$ value } \\
\hline & $\begin{array}{l}\text { No. of } \\
\text { SSCA }\end{array}$ & $\begin{array}{l}\text { No. of } \\
\text { SACA }\end{array}$ & $\begin{array}{l}\text { Total no. } \\
\text { of SCA }\end{array}$ & $\begin{array}{l}\text { No. of } \\
\text { SSCA }\end{array}$ & $\begin{array}{l}\text { No. of } \\
\text { SACA }\end{array}$ & $\begin{array}{c}\text { Total no. } \\
\text { of SCA }\end{array}$ & \\
\hline 1 & 24 & 7 & 31 & 17 & 8 & 25 & 0.55 \\
\hline 2 & 18 & 6 & 24 & 17 & 7 & 24 & 1.00 \\
\hline 3 & 14 & 10 & 24 & 20 & 3 & 23 & 0.05 \\
\hline 4 & 16 & 4 & 20 & 18 & 10 & 28 & 0.34 \\
\hline 5 & 14 & 10 & 24 & 20 & 10 & 30 & 0.58 \\
\hline 6 & 26 & 8 & 34 & 11 & 5 & 16 & 0.73 \\
\hline 7 & 19 & 8 & 27 & 13 & 8 & 21 & 0.56 \\
\hline 8 & 23 & 4 & 27 & 15 & 3 & 18 & 1.00 \\
\hline Total & 154 & 57 & 211 & 131 & 54 & 185 & \\
\hline
\end{tabular}

a Fishers' Exact Probability Test with calculations based on 2-sided probability.

\section{R E S ULT S}

\section{Sequential dominance}

The results of the analysis of sequential dominance are presented in Table 1.

A total of 211 SCAs (sequential controlling actions) were achieved by the male participants, among which 154 were SSCAs and 57 were SACAs. A total of 185 SCAs were performed by the female participants, among which 131 were SSCAs and 54 were SACAs. In order to see if there was a significant difference between the proportions of SSCAs and SACAs achieved by the male and the female participants in each dyad, Fisher's Exact Tests were performed on the eight dyads. Only Dyad 3 showed a significant difference $(p<0.05)$ between male and female, with female achieving 20 SSCAs out of 23 SCAs (87\%), whereas male achieved only 14 SSCAs out of 24 SCAs (58\%).

\section{Participatory dominance}

The results of the analysis of participatory dominance are presented in Table 2.

A total of 88 PCAs (participatory controlling actions) were performed by the male participants, among which 36 were PSCAs and 52 were PACAs. A total of 86 PCAs were performed by the female participants, among which 30 were PSCAs and 56 were PACAs. Among the eight dyads, Dyads 1, 6, and 8 showed significant differences between males and females in the proportions of PSCAs and PACAs achieved. In Dyad 1, the male participant achieved 7 PSCAs out of 11 PCAs (64\%), whereas the female participant did not achieve any PSCA out of 9 
TABLE 2. Participatory dominance: number of PSCAs and PACAs produced by male and female speakers in mixed gender dyads.

\begin{tabular}{|c|c|c|c|c|c|c|c|}
\hline \multirow[b]{2}{*}{ Dyad } & \multicolumn{3}{|c|}{ Male } & \multicolumn{3}{|c|}{ Female } & \multirow[b]{2}{*}{$p^{\text {a }}$ value } \\
\hline & $\begin{array}{l}\text { No. of } \\
\text { PSCA }\end{array}$ & $\begin{array}{l}\text { No. of } \\
\text { PACA }\end{array}$ & $\begin{array}{l}\text { Total no. } \\
\text { of PCA }\end{array}$ & $\begin{array}{l}\text { No. of } \\
\text { PSCA }\end{array}$ & $\begin{array}{l}\text { No. of } \\
\text { PACA }\end{array}$ & $\begin{array}{c}\text { Total no. } \\
\text { of PCA }\end{array}$ & \\
\hline 1 & 7 & 4 & 11 & 0 & 9 & 9 & 0.00 \\
\hline 2 & 5 & 8 & 13 & 4 & 9 & 13 & 1.00 \\
\hline 3 & 1 & 10 & 11 & 5 & 6 & 11 & 0.15 \\
\hline 4 & 3 & 5 & 8 & 4 & 4 & 8 & 1.00 \\
\hline 5 & 4 & 7 & 11 & 4 & 7 & 11 & 1.00 \\
\hline 6 & 8 & 4 & 12 & 1 & 11 & 12 & 0.01 \\
\hline 7 & 6 & 5 & 11 & 4 & 7 & 11 & 0.67 \\
\hline 8 & 2 & 9 & 11 & 8 & 3 & 11 & 0.03 \\
\hline Total & 36 & 52 & 88 & 30 & 56 & 86 & \\
\hline
\end{tabular}

a Fishers' Exact Probability Test with calculations based on 2-sided probability.

PCAs (0\%). In Dyad 6, the male participant achieved 8 PSCAs out of 12 PCAs (67\%), whereas the female participant achieved only one PSCA out of 12 PCAs $(8 \%)$. Both Dyads 1 and 6 showed significant participatory domination of male over female ( $p<0.00$ for the former and $p<0.01$ for the latter). Dyad 8 , however, showed significant female dominance over male $(p<0.05)$. In Dyad 8 , the male participant achieved 2 PSCAs out of 11 PCAs (18\%), whereas the female participant achieved 8 PSCAs out of 11 PCAs (73\%).

In the following section, we will conduct a qualitative analysis of the interactional features in three of these four dyads to explore the nature of gender dominance, or what underlies dominance identified through quantitative analysis. For sequential dominance, we will examine Dyad 3 because the statistical tests found that in this dyad, F was the dominant speaker. Although it would have been interesting to compare this dyad with a dyad that showed the opposite direction of gender dominance, we were unable to do so because there was no dyad that showed significant male dominance. Dyad 3 will therefore be compared with Dyad 6 as an example of dyad that did not show any clear male dominance. For participatory dominance, we will conduct a qualitative analysis on two dyads, 6 and 8, in order to compare male dominance in the former with female dominance in the latter.

QUALITATIVE ANALYSIS

\section{Sequential dominance: Dyad 3}

In this dyad, M3 produced 14 SACAs and F3 produced 20 SACAs. For M3, out of the 14 initiations, only one is an elicitation asking for agreement; the rest are 
informatives. For F3, out of the 20 initiations, 9 are informatives, 10 are elicitations asking for information, agreement, and confirmation, and one provides a suggestion. All instances of M3's informatives are about a secondary student whom he was giving private tuition and whom he describes as 'super weak' and unable to handle mathematical problems. These informatives receive supportive responses from F3. The following excerpt from turns 3 to 36 is typical of the interaction:

(3) M3 has told F3 that he has a part-time job.

3 M3: Soo. Kateikyoushi yatte $n$ da kedoo nanka chuugaku 3-nensee na no. Sugoi...

4 F3: $\quad$ Chuusan dattara juken de taihen jan.

5 M3: Choobaka dee. Ano sa Eigo no 'E' aru jan. 'E' wakannai no. De sansuu suugaku janakute moo sansuи no.

6 F3: Ett!?

7 M3: Ano saa doonatsu kooyuи sa kooyuи no koo natte tee koko no menseki motomen no an no. Sonde koko ga hankei ga 3 senchi de kokode 5 senchi tte nattetara kono 8 senchi no en kara 3 senchi no hikeba ii jan. Sore o futsuu setsumei sureba wakaru jan. Setsumei shite mo kore o hii-, hiku to kono menseki ga deru tte yиu koto ga wakannai kara moo doo shiyoo mo nai. "Sonna koto yatte deru n desu ka" toka kikarechatte. Daara "Koо уии no wa hiku n da yoo" toka itte oshiete...

I

[ Aa sore saa kami tsukutte sa "Ii ka. 8 senchi daro. Koo yatte 3 senchi kiru daro. Nakunaru jan" te yareba ii n da yo.

9 M3: Soo da kedo. Soo da kedo shikamo yaruki nai no zenzen.

$\rightarrow 10$ F3: Ett! Chuusan mazui yoo.

11 M3: Nde...

12 F3 Nn.

13 M3 Sonde ore ga oshie owaru jan, so su to ore to issho ni ie detettee asobi itchau noo.

14 F3: ((inaudible))

15 M3: Dakara moo saiaku da yo.

16 F3: Hee.

17 M3: "We" ga wakannai $n$ da yo.

$\rightarrow 18$ F3: "We" ga wakannai.

19 M3: "They" mo wakannai.

20 F3: Zenbu jaa wakannai jan soshitara.

21 M3: Soo soo soo.

22 F3: 'My name' gurai shika.

23 M3: Nn. "My name is" mo wakannai no.

$\rightarrow 24$ F3: Shinjirannai!

25 M3: ((inaudible)) gurai wakannai.

26 F3: 3 nen kan nani benkyoo shiten no.

27 M3: Sott. "bii-dooshi tte wakaru?" "Wakarimasen".

$\rightarrow 28$ F3: Sugoi seito motchatta nee.

29 M3: Nee.

30 F3: Taihen janai?

31 M3: Demo raku da yo, moo.

32 F3: ((laughs))

33 M3: Datte...

34 F3: A maa demo juken ni mukete tte yuu taihenna n janai kara nee. 
35 M3: Soo soo. Shiboo toka tte yuttee yakyuubu no aru kookoo toka kaite an no.

36 F3: Kuutt.

3 M3: 'Right. I' $m$ a private tutor but er my student is in his third year at his secondary school. He is extremely...'

4 F3:

'Looking after a third year student is difficult because of university entrance examinations, isn't it?'

5 M3: 'He is super weak. Let me tell you, he doesn't know what the letter alphabet ' $\mathrm{E}$ ' is and his level is arithmetic and not math.'

6 F3: 'Gosh!'

7 M3: 'Let me tell you. There was an exercise of measuring the area of a shape like a doughnut. The inside radius is $3 \mathrm{~cm}$ and the outside radius is $8 \mathrm{~cm}$ so we can get the answer by calculating the area measure of a circle with a radius of $8 \mathrm{~cm}$ and deducting the area measure of the inner circle with a radius of $3 \mathrm{~cm}$. Students usually understand this kind of explanation, don't they? But when I explained to him like if you subtra-, subtract this from this, he just can't understand it. He is just hopeless. He said something like, "Can I really get the answer like that?" So by saying that this kind of exercise needs subtraction,

8 F3: [ taught...'

'For that, if you use some paper saying, "Look, here is $8 \mathrm{~cm}$ and if we cut off the inner circle with $3 \mathrm{~cm}$ like this, it disappears", you can solve the problem, you know.'

9 M3: 'That's true. But he's got no motivation at all.'

$\rightarrow 10$ F3 'Oh no. It's hopeless if a third year student is like that.'

11 M3 'And er...'

12 F3 'Yes.'

13 M3 'And when I finish teaching, he leaves home with me to play.'

14 F3 ((inaudible))

15 M3 'So I'm in deep trouble.'

16 F3 'I see.'

17 M3 'He doesn't understand "we".'

$\rightarrow \quad 18 \quad$ F3 'He doesn't understand "we".'

19 M3 'He doesn't understand "they".'

20 F3 'He doesn't understand anything then, does he?'

21 M3 'Exactly.'

22 F3 "Maybe he only knows "My name is...",

23 M3 'Nn. He doesn't know "My name is...", either.'

$\rightarrow \quad 24 \quad$ F3 'This is absolutely incredible.'

25 M3 'He doesn't know' ((inaudible))

26 F3 'I wonder what he's been studying for 3 years.'

27 M3 'Right. When I ask him "Do you know "be" verbs?, he answers "I don't know".'

$\rightarrow 28$ F3 'You've got a real problem student, haven't you?'

29 M3 'Yes.'

30 F3 'Isn't it hard for you?'

31 M3 'It's O.K., now.'

32 F3 ((laughs))

33 M3 'Because...'

34 F3 'Ah yes, because you don't really have to be serious about the examinations, you know'

35 M3 'Right, right. In his application form, he's stated "I would like to apply for a senior high school that has a baseball club".'

36 F3 'Oh my goodness.' 
We can see from (3) that F3 plays a supportive role by echoing M3's informatives (turn 18), upgrading M3's negative evaluation of his student as 'super weak' and not motivated to 'hopeless' (mazui yoo) (turn 10) and 'incredible' (Shinjirannai!) (turn 24), and empathizing, 'You've got a real problem student, haven't you?' (Sugoi seito motchatta nee) (turn 28), and 'Oh my goodness!' ('Kuutt!') (turn 36).

The 20 initiations made by F3 are almost equally divided into informatives and elicitations. An analysis of the informatives produced by F3 shows that they are very different from those made by M3. All of the informatives made by M3 are self-oriented in the sense that they are on the topic that he wants to talk about, his private student and how weak he is. In contrast, out of the nine informatives produced by $\mathrm{F} 3$ that elicit acknowledgment or comments from M3, six express her lack of confidence in herself in giving private tuition; in other words, six of her informatives are self-denigrations. For example, in (2) above, turn 67, F3 expresses her lack of self-confidence to be a private tutor. Instead of responding with a positive evaluation of $\mathrm{F} 3$, which is a preferred response to a self-denigration (Pomerantz 1984, Tsui 1994), M3 affirms that F3's negative evaluation of herself is well founded. F3's diffidence stands in strong contrast to M3's self-confidence expressed in turn 70, to which F3 responds with an oh-receipt acknowledgment (Drew 1984) and an agreement. The only instance where F3 makes a positive evaluation of herself is in turn 46 in (4):

(4) Continuation of excerpt 3.

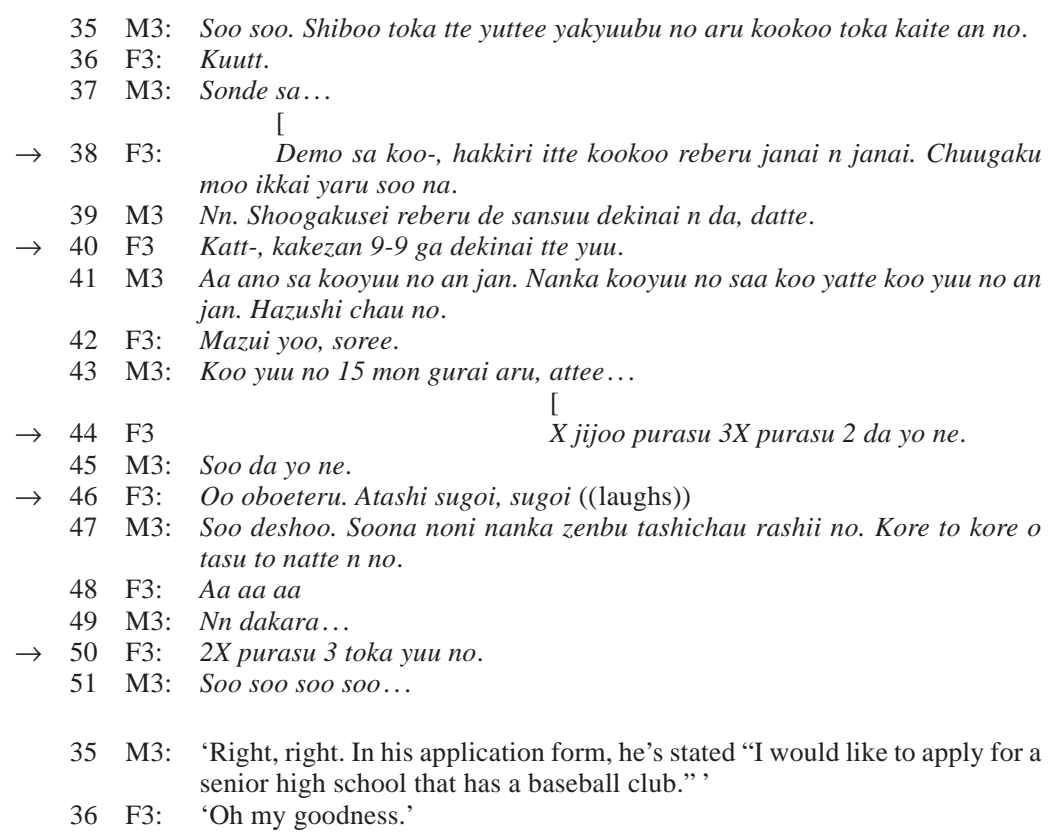




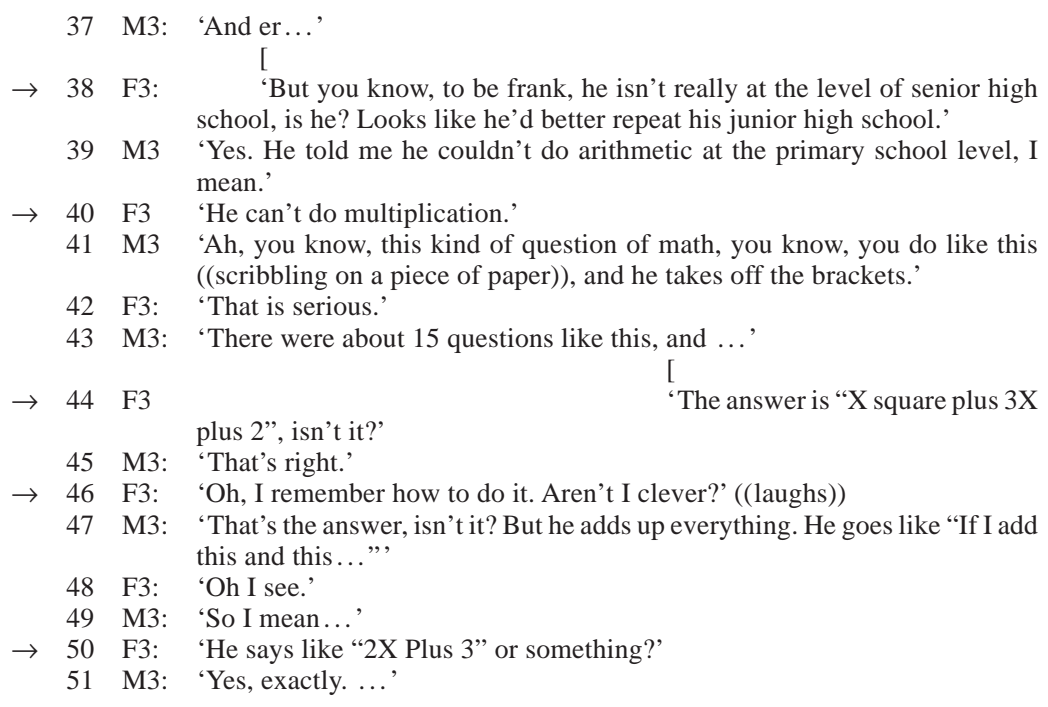

In turn 46, F3 is pleased with herself for being able to get the right answer to a mathematical problem. However, this was not responded to with a positive evaluation from M3, but simply with a reaffirmation of the answer she gave, followed by a description of how his student handled the problem.

The ten elicitations made by F3 consist mostly of elicitations that ask for more information about M3's job as a private tutor - such as where he found the job, the average rate paid for private tuition, whether the job was difficult for him - and those that ask for confirmation of her interpretation of the information provided by M3, or seek agreement from M3 with her opinion. Excerpt (4) contains four elicitations that are typical of the interaction. In turn 38, on the basis of the information provided by $\mathrm{M} 3$ about his private student, F3 makes an evaluation of the student and invites M3 to agree with it. In turns 40, 44, and 50, she asks for confirmation from M3. In all four instances, M3 is the source of information and hence authority. F3's lack of self-confidence can be seen best in her deference to M3 for a verdict in turn 44.

To summarize, qualitative analysis of sequential dominance in Dyad 3 suggests that, although quantitative analysis of controlling actions on this dimension shows female dominance, the female speaker's initiations tend to be informatives that are used to echo the male speaker's views and empathize with them, or to express lack of self-confidence, and the elicitations are addressee-oriented questions or clarification questions used to encourage the male speaker to elaborate on his story. As for the male speaker, although quantitative analysis found him to be dominated, most of his informatives are used to pursue his own storytelling, and his initiations support rather than contradict F3's self-denigration. The analysis 
therefore suggests that M3's initiations reflect self-oriented conversational style, and F3's initiations other-oriented conversational style.

\section{Sequential dominance: Dyad 6}

The quantitative analysis of this dyad shows no significant gender domination. Their conversation is mostly on the topic of living abroad and learning English. Prior to the 100 turns that were part of the corpus analyzed in this study, M6 tells F6 that he lived abroad for more than two and a half years. F6 then tells M6 about her one-month visit to Canada. However, in F6's account, she portrays herself in a negative way, saying that she was not able to 'speak much English' and that she got through an examination and an interview by sheer luck.

M6 achieves 26 instances of SSCA out of 34 SCAs (76.5\%). The SSCAs consist of 17 informatives, 8 elicitations and one "challenging move" (Burton 1981) that challenges the presupposition of the preceding move. An analysis of the SSCA sequences and their relation to the topic of talk will provide a better understanding of the nature of the interaction. Let us start with M6's informatives.

The informatives produced by M6 are mainly on the topic of studying abroad and learning English, both overseas and in Japan. Through these informatives, M6 tries to reinforce the claim to expertise that he has established earlier in the conversation because he has lived abroad much longer than F6. As the conversation develops, M6's claimed expertise appears to have become a shared assumption that allows him to speak with authority on the subject of learning English.

Excerpt (5) is a typical example of the informatives produced by M6 to reinforce his claim to expertise. He establishes his expertise not only based on his length of stay overseas and his knowledge of English, but also on his knowledge of universities in Australia and how difficult it is to graduate from these universities:

(5) F6 has never studied in an Australian university and she wants to try. M6 discourages her from trying by telling her his experience at an Australian university where he stayed.

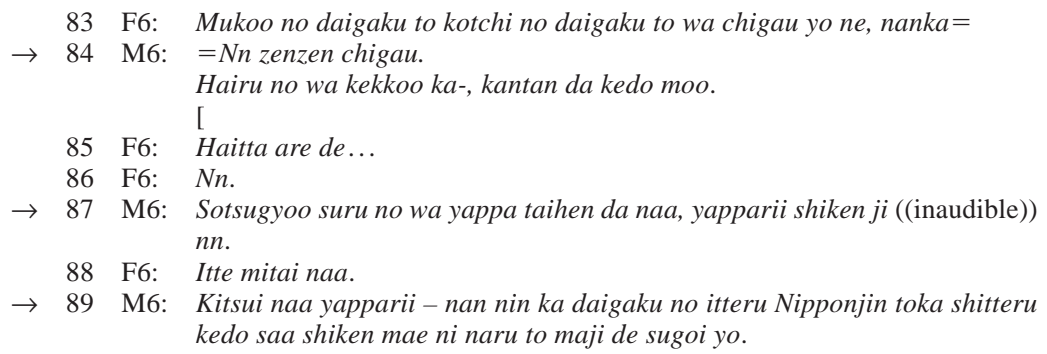
kedo saa shiken mae ni naru to maji de sugoi yo.

83 F6: 'Universities overseas and universities in Japan are different, in a way, aren't they?'=

$\rightarrow 84$ M6: = 'Yes, absolutely different. Entering is quite ea-, easy, though.'

85 F6:<smiles>[CH]1CCC1</smiles>
'Entering er...' 


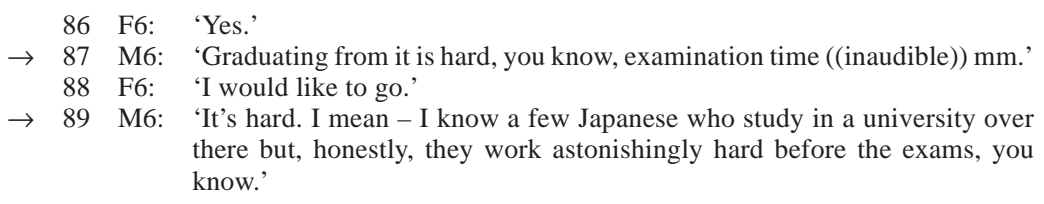

Earlier in the conversation, F6 has indicated that she wants to visit Australia. M6, in turns 84,87 , and 89 , reports on university life there. However, the upshot of these reports (Drew 1984) seems to suggest that it may be too difficult for F6 to keep up with her study at an Australian university. This can be seen from the fact that when F6 indicates that she would like to go and study at an Australia university, M6 ignores her. Instead, he just carries on with his previous turn by reiterating that it is hard to graduate from these universities, and he supports his claim by citing examples of his Japanese friends. In the subsequent development of the conversation, M6's implicit suggestion is made explicit when F6 says that, given such tough requirements, there would be 'absolutely no hope' for her, and M6 agrees. ${ }^{2}$

Let us now turn to M6's elicitations. There are eight instances, and they are used in chains of initiations together with informatives, which facilitates his claim to expertise in learning English.

(6) M6 is talking about his experience of not being able to understand English, including the expression 'See you', when he first visited Australia.

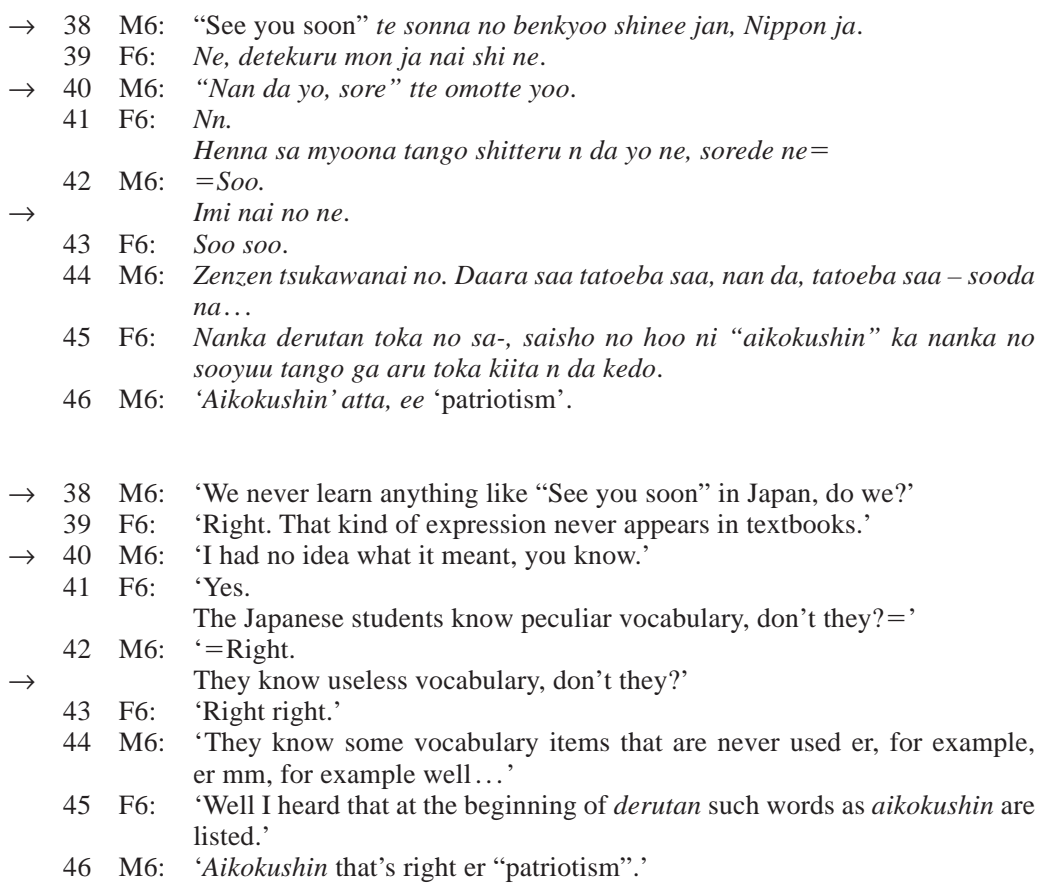


In turn 38, M6 criticizes English teaching in Japan by eliciting F6's agreement that common expressions such as 'see you' are not taught. This elicitation is linked to his informative in turn 40 and to his elicitation in turn 42 , thereby forming a chain of initiations in which he claims expertise on English teaching in Japan. Similar to his use of informatives, M6 uses elicitations to demonstrate his expertise through his criticisms of how poorly English is taught in Japan. The vocabulary taught is criticized as 'useless' and 'never used'.

F6 achieves 11 instances of SSCAs out of 16 SCAs (69\%), of which four are informatives and seven are elicitations. Among the seven elicitations that she produces to which she successfully obtains responses, three invite M6 to provide further information on a topic that M6 has introduced. Turn 15 in (7) is an example of this:

(7) M6 has been telling F6 about a friend he met overseas whose English is very good.

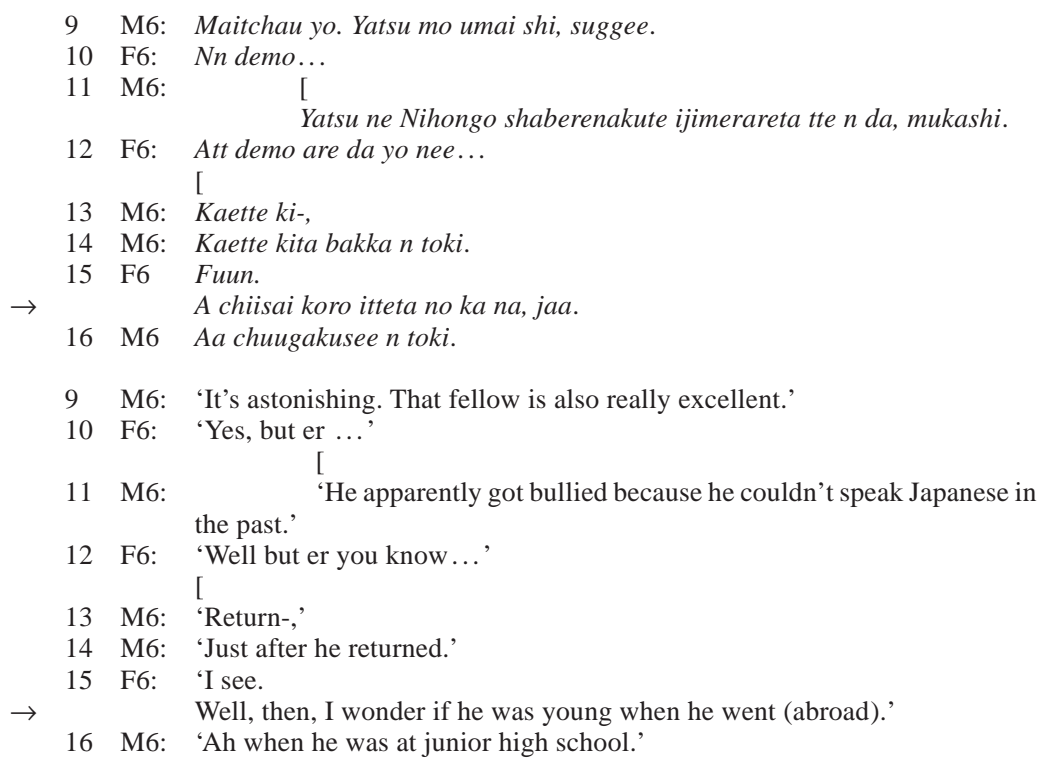

Of the remaining elicitations, two ask for confirmation from M6, which acknowledges his authority with regard to information about universities overseas and learning English.

As for F6's four informatives that elicit acknowledgment or comments from M6, one serves to elaborate on the topic that M6 has introduced, and one is a self-denigration in which she describes herself as 'such a hopeless or inadequate, or incapable person like myself' (watashi nanka). (In Japanese, nanka is often used after watashi 'me' to provide the additional meaning of 'hopeless, inadequate, incapable'.) When F6's informatives change the topic, M6 shows a lack of interest, and subsequently F6 returns to the topic previously introduced by M6. For example: 
(8) Prior to this excerpt, M6 has been describing his class in some detail.

24 F6: ... Hee uchi nanka demo ne uchi no kurasu mo ne ii kurasu tte iwareteru n da yo. Sensei ga are kamoshinnai kedo hagemasu tame ni itteru dake kamoshinnai kedo.

25 M6: Hoka no kurasu ga doona no ka wakannai kara saa.

26 F6: Aa sore mo aru yo nee.

((pause))

27 F6: Demoo nanka nani hokano sono hen de nanka /LI/ sensei toka ni atte hanasu to nani kekkoo nani mo shaberenakute saa nanka nani shitt-, kaiwa shiyoo to mo shinaide nanka suutte nigechau hito toka ni.

28 M6: Aa hontoo

29 F6: Nihon ja shaberenai deshoo.

30 M6: $\quad N$ ?

31 F6: Nihon no kookoo no jugyoo sonomama uketete daigaku juken no benkyoo shita dake ja shaberenai deshoo.

32 M6:

33 F6:

[

Nee.

34 M6: Hotondo muri da ne. Ore mo ichioo daigaku juken shita kara aru teido tango wa motteta kedo mukoo iku mae ni shaberenakatta mon ne.

35 F6: Nee.

36 M6: Daara "See you soon" te iwarete saa "Arigatoo gozaimasu" tte ta mon.

37 F6: ((laughs))

24 F6: '...Hmm but my class, you know, my class is also said to be a good class, you know, some teacher said so, although he may have just meant to be encouraging.'

25 M6 'I don't know what other classes are like.'

26 F6 'Oh that's right.'

((pause))

27 F6: 'But er, what is it, others, when they talk to their [English] teachers around there, they can't say anything, you know, er, what is it, they don't even try to hold a conversation, with those people who ran away.'

28 M6: 'Oh really.'

29 F6: 'We won't be able to speak in Japan, right?'

30 M6: 'What?'

31 F6: 'Just receiving English classes at school in Japan and studying for university examinations does not help the students to be able to $=$,

32 M6:

[

- 'offers no chance, you see $=$ '

33 (31F6:) ='speak English, right?'

35 F6: 'Right.'

34 M6: 'It's almost impossible, you know. I took university entrance examinations so I knew some English vocabulary but I could hardly speak any English before I went there (=Australia), you see.'

35 F6: 'Right.'

36 M6: 'So when somebody said to me, "See you soon", I responded "Thank you very much".'

37 F6: ((laughs))

After having listened to M6's detailed description of his class, F6 attempts to describe her own class in turns 24 and 27. However, her attempt to shift the topic from M6's class to F6's class is unsuccessful because M6 expresses a lack of interest in listening to F6's report in turn 25 and produces a minimal 
acknowledgment with no elaboration in turn 28. As in turn 88 in (5), F6 is unsuccessful in developing the topic concerning herself and her experience. However, as soon as F6 changes the topic back to the one in which M6 claims expertise, he responds more enthusiastically and continues to develop the topic (turns 34-37).

To summarize, the analysis of sequential dominance in Dyad 6 shows that, by skillfully using his informatives to create a gap between the two speakers in the amount of experience relevant to the topic under discussion, the male speaker assumed the role of an expert. His assumption of this role is supported by the female speaker in different ways. First, she accepts the male speaker's claim of superior knowledge and experience with her response moves. Second, she facilitates further development of the male speaker's topic by inviting him to provide further information on his topic of talk. Third, she lowers her own position by self-denigration. The female speaker's attempt to take control over the topic is inhibited by the male speaker's lack of interest. Thus, similar to the findings from Dyad 3, the male speaker's initiations seem to indicate his self-oriented conversational style, and the female speaker's initiations indicate other-oriented conversational style, and these styles seem to interact with each other to accomplish male dominance.

\section{Participatory Dominance: Dyad 6}

In Dyad 6, the male speaker (M6) achieves 8 instances of PSCAs (participatory successful controlling actions) out of 12 PCAs (participatory controlling actions) $(67 \%)$, whereas the female speaker (F6) achieves only one PSCA out of 12 PCAs (8\%). The eight instances of PSCA by M6 consist mainly of M6's continuing his control over the topic, either when F6 is about to contradict him or when F6 is developing the topic. For example, in (5) above, F6 tries to come in at the first possible completion point of turn 84 to develop her elicitation for agreement in turn 83. However, M6 holds onto his turn, and F6 relinquishes the floor. In (7), turn 10, just as F6 is going to put forth something contrary, her turn is interrupted. In turns 12 and 13, there is an overlap and F6 relinquishes her turn, whereas M6 reiterates the topic in turn 14. F6 goes along with M6's topic control and produces an acknowledgment followed by an elicitation to enable M6 to develop the topic further.

When F6's turns are interrupted by M6 or when there is an overlap, she readily relinquishes the floor and allows M6 to take control. However, when she tries to interrupt M6 and introduce contrary views, M6 seldom relinquishes his turn. Consequently, the conversation develops very much around topics that are oriented to M6 rather than to F6, allowing him to claim superior knowledge and expertise. It also puts F6 in a position where the only role she is allowed to play is that of a subservient supporter to M6. 


\section{Participatory dominance: Dyad 8}

In Dyad 8, the male speaker (M8) achieves 2 PSCAs out of 11 PCAs (18\%), and the female speaker (F8) achieves 8 PSCAs out of 11 PCAs (73\%), showing female dominance (see Table 2).

The two instances of PSCAs achieved by M8 discourage F8 from developing her topic either by withholding interest in her topic or by displaying his superior knowledge or experience. Below is an example of this:

(9) M8 and F8 are talking about courses that they are taking at university.

$$
\begin{aligned}
& \text { M8: } D e \ldots \\
& \text { F8: Datte tsuman nai, (Nichirin) to Bunkajin... Anthropology... } \\
& \rightarrow 3 \text { M8: Bunkajinrui wa ikkai shika dete nai kara wakaranai. } \\
& \text { M8: 'And ...' } \\
& 2 \text { F8: 'Because they are boring, (Japanese ethics) and Anthropo- ...' } \\
& \rightarrow 3 \text { M8: 'I don't know anything about Anthropology because I've attended it only }
\end{aligned}
$$

In turn 3, M8 interrupts F8 to express a lack of interest in continuing her topic, some of the courses that she is taking ('I don't know anything about Anthropology...').

As for F8's eight PSCAs, five of them are used to show her interest in her male interlocutor's storytelling through offering her comments, clarification questions, or addressee-oriented questions that facilitate expansion of his talk; two are used to express her self-denigration or inferior experience, and the remaining one attempts to continue her topic of talk but fails. The collaborative nature of her interruptions is illustrated in (10):

(10) M8 is talking about a karaoke bar that he has been to.

85 M8: 5 ji go-, goji ikou iku to 1 jikan 3,000 en. 5 ji mae ni iku to 1 jikan 1,500 en ka na.

86 F8: Aa.

87 M8: So nanka sore wa futsuu nanda kedo, mm...

$\rightarrow \quad 88$ F8: $\quad$ Jaa ii ne. Futsuu da ne..

89 M8: Sugoi kirei da yo - demo ne, chotto omoshiroku nai no ga, kyoku ireru to kekkyoku kekkou saa ( ) are ireru too dechau no.

90 F8: Aa.

91 M8: Dechau no, koo yatte...

$\rightarrow 92$ F8: [ Nani, kyok-, kyokumei made dechau no?

93 M8: Kyokumei ga dechau no.

94 F8 Att, dame jaan.

95 M8 Naanka dame da yo, datt-, tanoshimi ga nakunatchau.

96 F8 Soo da yo nee.

85 M8: 'If you go ar-(round), after 5 o'clock, it's 3,00 yen per hour. But if you go there before 5, it's 1,500 yen per hour, I guess. .'

86 F8: 'Oh I see.' 


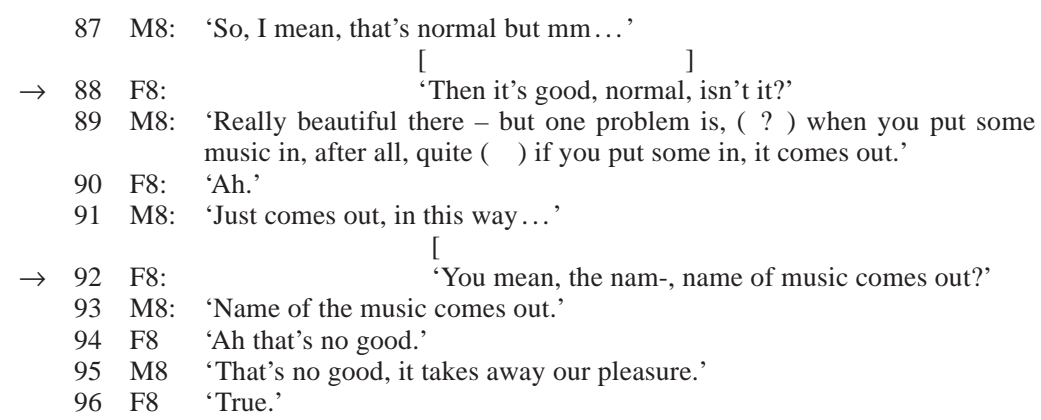

In turn 88, F8 interrupts M8 and stops M8 from completing his turn, but her interrupting utterance in fact conveys her interest in his storytelling. Similarly, her interruption in turn 92, where she asks a clarification question, helps M8 to develop his story further. F8's interruption (turn 92), his response (turn 93), and her follow-up (turn 94) comprise an inserted sequence that holds up M8's storytelling temporarily but helps him to elaborate on its details.

In addition to two PSCAs (participatory successful controlling actions), M8 produces nine PACAs (participatory attempted controlling actions), where he does not complete his utterance following F8's interruption. However, in the majority of these cases (6 of 9), F8's interruptions in fact elicit further information or clarification of M8's story and therefore play a facilitating role.

\section{I S C U S S I O N}

If the findings of the quantitative analysis were to be considered separately from those of the qualitative analysis, the participants' interactional behavior in most of the dyads might be described as displaying no gender dominance. However, if we see them in the context of the entire conversation and the way the features identified have shaped the development of the conversation, we can understand the situation differently.

Although the quantitative analysis of sequential dominance conducted on the eight dyads did not show any obvious pattern of male dominance, the qualitative analysis of the same dimension revealed self-oriented conversational style for the male speakers and other-oriented conversational style for the female speakers. These two different conversational styles contributed to the asymmetrical relationship between male and female, with the male speaker playing the dominant role. The male speakers' self-oriented conversational style on the dimension of sequential dominance was manifested in their pursuit of center stage in storytelling, claiming expertise, and gaining the status of an authority figure. To these ends, they used various kinds of discourse strategies: using initiating moves (informatives) to create a gap between their knowledge and experience relevant to the topic and those of the female speakers; claiming superior experience relevant to the topic and aligning with a powerful persona; and agreeing with a female 
speaker's self-denigration or undermining her confidence. In addition, the male speakers used informatives to defend their topic control and preempt attempts to take control by female speakers. The male speakers' informatives were therefore used to create a gap between the two speakers in level of knowledge and amount of experience relevant to topic development, in order to raise the males' status or lower that of the females. In contrast, female speakers appeared to use initiating moves mostly to support the male speakers' storytelling in various ways - for example, by showing interest, asking for more details, endorsing male speakers' claim of superior knowledge and expertise, deferring to their authority, creating opportunities for them to demonstrate their superior knowledge and expertise, and expressing self-denigration.

Findings from the qualitative analysis of participatory dominance resemble those from that of sequential dominance: Regardless of the different directions of gender dominance found in the quantitative analysis, the male speakers seem to have used interruptions along with self-oriented conversational styles, and the female speakers along with other-oriented conversational styles. The male speakers tended to interrupt the female speakers when the female speakers started to present a contrary view, and they resumed their storytelling immediately following the interruption. In contrast, the female speakers' interruptions mostly supported the male speakers' storytelling by way of clarification questions or addressee-oriented questions that encouraged the male speakers to elaborate on their story, or through comments on it. When the male speakers resumed their topic after being interrupted, the female speakers readily supported their resumption of topic. Thus, although the female speakers' interruptions constrained the male speakers' participatory right temporarily, they normally served the function of an inserted sequence that provided the male speakers opportunities to elaborate on their talk. Female speakers' interruptions also expressed self-denigration, in which they displayed their supposedly inferior knowledge and experience relevant to the topic.

In sum, the qualitative analyses on these dimensions of conversational dominance showed that male speakers' self-oriented conversational style and female speakers' other-oriented conversational style are complementary and mutually reinforcing rather than competing. In other words, male dominance is not something predetermined and imposed upon female speakers. It is instead mutually constructed by the two parties.

The study also confirms the importance of integrating qualitative analysis and quantitative analysis. Only by doing this are we able to situate the production of interactional features (see Freed \& Greenwood 1996, Uchida 1992) and to uncover intricate relationships among power, conversational style, and interactional strategies (see Kiesling 1998). The integrated approach taken in this study, therefore, opens up the possibility for investigating different ways in which "doing gender" is accomplished within specific contexts. This would allow us to see "doing gender" as a composite of conversational styles and goals, and the discourse strat- 
egies that underlie them, leaving opportunities for individual speakers to take an active role in using different components to suit their own gender identity.

\section{O N C L U S I O N}

In this article, we have investigated the phenomenon of gender and conversational dominance and how it can be described adequately and interpreted on the basis of conversational data from dyads of mixed gender. We proposed a framework of analysis based on Linell et al.'s (1988) notion of controlling action, and the premise that interactional features are highly situation-specific, and that they should not be taken as indicative of conversational dominance without considering their relation to the preceding and subsequent discourse. We focused on two important dimensions of conversational dominance: sequential dominance and participatory dominance. The quantitative analyses of each dimension did not show any obvious tendency of gender dominance if they were taken separately and not in the context of the conversational goals of the speakers. However, when they were taken together and as situated in the specific contexts of the conversations, there was a clear tendency of male dominance over female. This suggests that conversational dominance is multifaceted, and that it would be misleading to just take a single interactional feature and draw conclusions on the basis of its frequency of occurrence.

The qualitative analysis of three dyads that showed different patterns of gender dominance presented remarkable similarities. There was a strong tendency of male dominance over females in all three: Males played a central role in shaping the development of the conversation; all the conversations evolved around the interests of the male speakers; and the female speakers were forced to play a subservient role and their contributions to the conversation were trivialized. Such differences can hardly be explained away as mere differences in conversational style and in the orientation of people being brought up in different subcultures. The findings we have reported suggest that it is very important to examine instances of dominance in the light of how they are related to the rest of the conversation, how dominance affects the development of the topic of talk, how it shapes the dynamics of conversational interaction, and what impact it has on the achievement of conversational goals. Moreover, they suggest that gender dominance in conversation is dialectical, jointly constituted by the behaviors of the male and the female speakers.

\section{A P P E N D I X}

Transcription conventions (adapted from Jefferson 1984 and Tsui 1994)

Beginning of overlapping utterances
End of overlapping utterances
A single speaker's utterance which is a continuous flow of speech but has been
separated graphically in order to accommodate intervening interruption or
A second utterance being latched immediately to the first utterance with no overlap.




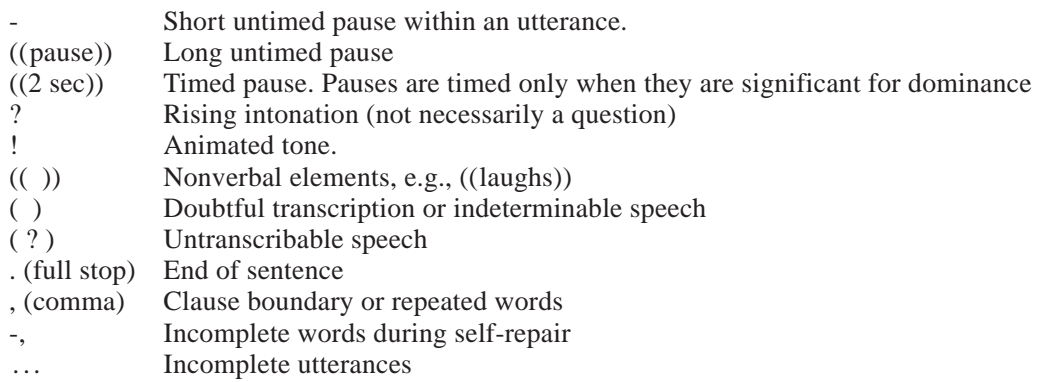

\section{NOTES}

* The authors wish to thank Dwight Atkinson, Andy Curtis, Jane Hill, and two anonymous reviewers for their encouragement and valuable comments on earlier drafts of the paper. They also wish to thank Simon Lai, senior research assistant, for his help in conducting the statistical test.

${ }^{1}$ Kiesling's quantitative analyses captured different patterns in the pronunciation of -ing among the male graduates seeking to join an American fraternity club: While some members showed a higher rate of use of vernacular variant - in' in formal weekly meetings than in informal social gatherings, others showed the opposite tendency. Kiesling's qualitative analyses revealed that although all of them wanted to impress the seniors by the way they talked, those from a working-class background tended to use the vernacular -in' more in formal meetings to demonstrate their values associated with hard work, physical power, and camaraderie, whereas those from a middle-class background tended to use the standard -ing more in formal meetings to display their identity based on their socioeconomic and structural power.

${ }^{2}$ Because of space limitations, this part of the transcript is not presented (for the whole transcript, see Itakura 2001a).

\section{REFERENCES}

Baron, Bettina, \& Kotthoff, Helga (eds.) (2002). Gender in interaction: Perspectives on femininity and masculinity in ethnography and discourse. Amseterdam: John Benjamins.

Burton, Deidre (1981). Analysing spoken discourse. In Malcolm Coulthard \& Martin Montgomery (eds.) Studies in Discourse Analysis, 61-81. London: Routledge.

Coates, Jennifer (1996). Women talk. Oxford: Blackwell.

(1997). One-at-a-time: The organization of men's talk. In Sally Johnson \& Ulrike Hanna Meinhof (eds.), Language and masculinity, 107-29. Oxford: Blackwell.

Coulthard, Malcolm, \& Brazil, David (1981). Exchange structure. In Malcolm Coulthard \& Martin Montgomery (eds.), Studies in discourse analysis, 82-106. London: Routledge.

DeFrancisco, V. L. (1998). The sounds of silence: How men silence women in marital relations. In Jennifer Coates (ed.), Language and gender: A reader, 176-84. Oxford: Blackwell.

Drew, Paul (1984). Speakers' reportings in invitation sequences. In J. Maxwell Atkinson \& John Heritage (eds.), Structures of social action, 129-51. Cambridge: Cambridge University Press.

Drew, Paul, \& Heritage, John (1992). Analysing talk at work: An introduction. In Paul Drew \& John Heritage (eds.), Talk at work: Interaction in institutional settings, 3-65. Cambridge and New York: Cambridge University Press.

Fishman, Pamela M. (1983). Interaction: The work women do. In Barrie Thorne et al. (eds.), Language, gender and society, 89-101. Cambridge, MA: Newbury House.

Freed, Alice F., \& Greenwood, Alice (1996). Women, men, and type of talk: What makes the difference? Language in Society 25:1-26.

Grimshaw, Allen D. (1987). Finishing other's talk: some structural and pragmatic features of completion offers. In Ross Steele \& Terry Threadgold (eds.), Language topics, essays in honour of Michael Halliday, 213-35. Amsterdam: John Benjamins. 
Gunnarsson, Britt-Louise (1997). Women and men in the academic discourse community. In Helga Kotthoff \& Ruth Wodak (eds.), Communicating gender in context, 219-48. Amsterdam: John Benjamins.

Hirschman, Lynette (1973). Female-male differences in conversational interaction. Paper presented at annual meeting of the Linguistic Society of America, San Diego, CA. [Published in Language in Society 23:427-42, 1994.]

Holmes, Janet (1984). Hedging your bets and sitting on the fence: Some evidence for hedges as support structures. Te Reo 27:47-62.

(1995). Women, men and politeness. London: Longman.

Ide, Sachiko (1992). Gender and function of language use: Quantitative and qualitative evidence from Japanese. Pragmatics and Language Learning 3:117-29.

Itakura, Hiroko (2001a). Conversational dominance and gender: A study of Japanese speakers in first and second language contexts. Amsterdam: John Benjamins

(2001b). Describing conversational dominance. Journal of Pragmatics 33:1859-80.

James, Deborah, \& Clarke, Sandra (1993). Women, men and interruptions: A critical review. In Deborah Tannen (ed.), Gender and conversational interaction, 231-280. New York: Oxford University Press.

Jefferson, Gail (1984). Transcription notation. In J. Maxwell Atkinson and John Heritage (eds.), Structures of social action, ix-Xvi. Cambridge and New York: Cambridge University Press.

Kendall, Shari, \& Tannen, Deborah (1997). Gender and language in the workplace. In Ruth Wodak (ed.), Gender and discourse, 81-105. London: Sage.

Kiesling, Scott Fabius (1998). Men's identities and sociolinguistic variation: The case of fraternity men. Journal of Sociolinguistics 2:69-99.

Leet-Pellegrini, Helena M. (1980). Conversational dominance as a function of gender and expertise. In Howard Giles et al. (eds.), Language: Social psychological perspectives, 97-104. Oxford: Pergamon.

Linell, Per (1990). The power of dialogue dynamics. In Ivana Markovà \& Klaus Foppa (eds.), The dynamics of dialogue, 147-77. Hemel Hempstead: Harvester Wheatsheaf.

\& Luckmann, Thomas (1991). Asymmetries in dialogue: Some conceptual preliminaries. In Ivana Markovà \& Klaus Foppa (eds.), Asymmetries in dialogue, 1-20. Hemel Hempstead: Harvester Wheatsheaf.

; Lennart Gustavsson; \& Juvonen, Päivi (1988). Interactional dominance in dyadic communication: A presentation of initiative-response analysis. Linguistics 26:415-42.

Murray, Stephen O. (1998). The sound of simultaneous speech, the meaning of interruption. Journal of Pragmatics 12:115-16.

\& Covelli, Lucille H. (1988). Women and men speaking at the same time. Journal of Pragmatics 12:103-11.

Okamoto, Shigeko (1995). "Tasteless Japanese": Less "feminine" speech among young Japanese women. In Kira Hall \& Mary Buchholtz (eds.), Gender articulated: Language and the socially constructed self, 297-325. New York \& London: Routledge.

Pomerantz, Anita (1978). Compliment responses: Notes on the co-operation of multiple constraints. In Jim Schenkein (ed.), Studies in the organization of conversational interaction, 79-112. New York: Academic Press.

(1984). Agreeing and disagreeing with assessments: Some features of preferred/dispreferred turn shapes. In J. Maxwell Atkinson \& John Heritage (eds.), Structures of social action, 57-101. Cambridge: Cambridge University Press.

Rommetveit, Ragnar (1987). Meaning, context, and control: Convergent trends and controversial issues in current social-scientific research on human cognition and communication. Inquiry 30:77-99.

Sacks, Harvey (1992a). Lectures on Conversation, vol. 1. Gail Jefferson (ed.). Cambridge, MA: Blackwell.

(1992b). Lectures on Conversation, vol. 2. Gail Jefferson (ed.). Cambridge, MA: Blackwell.

Schegloff, Emanuel A., \& Sacks, Harvey (1973). Opening up closings. Semiotica 7:289-327.

Sinclair, John McH., \& Coulthard, Malcolm (1975). Towards an analysis of discourse: The English used by teachers and pupils: Oxford: Oxford University Press.

Tannen, Deborah (1986). That's not what I meant! How conversational style makes or breaks your relations with others. New York: William Morrow. 

Morrow.

(1990). You just don't understand: Women and men in conversation. New York: William (1994). Gender and discourse. New York: Oxford University Press.

Tsui, Amy B. M. (1991). The interpretation of language as code and language as behavior: A description of evaluative statements. In Eija Ventola (ed.), Functional and systemic linguistics: Approaches and use, 193-212. Berlin: Mouton de Gruyter.

(1994). English conversation. Oxford: Oxford University Press.

Uchida, Aki (1992). When "difference" is "dominance": A critique of the "anti-power-based" cultural approach to sex differences. Language in Society 21:547-68.

Uchida, Nobuko (1997). Kaiwa koodoo ni mirareru seesa [Gender differences in conversation]. In Sachiko Ide (ed.), Joseego no sekai [The world of women's language]. 74-93. Tokyo: Meeji Shoin.

West, Candace, \& Fenstermaker, Sarah (2002). Accountability in action: the accomplishment of gender, race and class in a meeting of the University of California Board of Regents. Discourse and Society 13:537-63.

\& Garcia, Angela (1988). Conversational shift work: A study of topical transitions between women and men. Social Problems 35:551-75.

\& Zimmerman, Don H. (1983). Small insults: A study of interruptions in cross-sex conversations between unacquainted persons. In Barrie Thorne et al. (eds.), Language, gender and society, 102-17. Cambridge, MA: Newbury House.

(1987). Doing gender. Gender and Society 1:125-51.

Wodak, Ruth (ed.) (1997). Gender and discourse. London: Sage.

Zimmerman, Don H., \& West, Candace (1975). Sex roles, interruptions and silences in conversation. In Barrie Thorne \& Nancy Henley (eds.), Language and sex: Difference and dominance, 105-29. Rowley, MA: Newbury House.

Woods, N. (1988). Talking shop: Sex and status as determinants of floor appointment in a work setting. In Jennifer Coates \& Deborah Cameron (eds.), Women in their speech communities, 14157. London: Longman.

(Received 8 October 2001, accepted 13 October 2002, final revision received 21 October 2002) 